\title{
A Novel Rutin Electrochemical Sensor Using Reduced Graphene Oxide/Magnetite/Silver Nanoparticle-Molecularly Imprinted Polymer Composite Modified Electrode
}

\author{
Shiru Yang ${ }^{1}$, Xin Yang ${ }^{1,2, ~ *}$, Rong Tang ${ }^{1}$, Lizhi Xiong ${ }^{3}$, Yaqi Yang ${ }^{1}$, Yangjian Hu ${ }^{1}$, Chunmei Zhang ${ }^{1}$, \\ Zijian Zhao, * \\ ${ }^{1}$ Hunan Engineering Laboratory for Preparation Technology of Polyvinyl Alcohol Fiber Material, \\ College of Chemistry and Materials Engineering, Huaihua University, Huaihua, 418000, P.R. China; \\ ${ }^{2}$ Key Laboratory of Research and Utilization of Ethnomedicinal Plant Resources of Hunan Province, \\ College of Biological and Food Engineering, Huaihua University, Huaihua, 418000, P.R. China; \\ ${ }^{3}$ College of Materials and Chemistry Engineering, Hunan City University, Yiyang, 413000, P.R \\ .China; \\ *E-mail: 01yangxin@163.com (X. Yang); zjzhao72@163.com (Z.J. Zhao).
}

doi: $10.20964 / 2018.03 .55$

Received: 13 November 2017 / Accepted: 8 December 2017 / Published: 5 February 2018

A novel rutin (RT) electrochemical sensor was fabricated by using reduced graphene oxide (rGO)/magnetite $\left(\mathrm{Fe}_{3} \mathrm{O}_{4}\right)$ /silver nanoparticle $(\mathrm{Ag})$-molecularly imprinted polymer (MIP) composite to modify screen-printed electrode (SPE). The ternary composite of $\mathrm{rGO} / \mathrm{Fe}_{3} \mathrm{O}_{4} / \mathrm{Ag}$ was prepared by the one-step solvothermal method. Subsequently, RT molecules were absorbed on the surface of rGO/ $\mathrm{Fe}_{3} \mathrm{O}_{4} / \mathrm{Ag}$ due to the electrostatic force. Finally, the MIP was achieved by a polymerization reaction. The prepared composite was investigated by FTIR, XRD and VSM. The morphologies and electrochemical properties of different electrodes were characterized with FE-SEM, EIS, CV and DPV. Under the optimal conditions, the SPE $\mid \mathrm{rGO} / \mathrm{Fe}_{3} \mathrm{O}_{4} / \mathrm{Ag}$-MIP electrode exhibited highly sensitive and selective in determining of RT. The linear detection ranges (LDRs) were $1.0 \times 10^{-2}$ to $10.0 \mu \mathrm{M}$ $(R=0.9978)$ and 10.0 to $3.0 \times 10^{3} \mu \mathrm{M}(R=0.9965)$. The limit of detection (LOD) was as low as $4.2 \times 10^{-3}$ $\mu \mathrm{M}(S / N=3)$. The proposed electrode was renewable, stable and reliable. It was used for determining RT in pharmaceutical samples with satisfactory results, confirming its promising application in routine RT analysis.

Keywords: Rutin; Reduced graphene oxide; Magnetite; Silver nanoparticles; Molecular imprinted polymer; Screen-printed electrode

\section{$\underline{\text { FULL TEXT }}$}


(C) 2018 The Authors. Published by ESG (www.electrochemsci.org). This article is an open access article distributed under the terms and conditions of the Creative Commons Attribution license (http://creativecommons.org/licenses/by/4.0/). 